\title{
IV. Elastic constants of rocks and the velocity of seismic waves
}

\section{H. Nagaoka}

To cite this article: H. Nagaoka (1900) IV. Elastic constants of rocks and the velocity of seismic waves, Philosophical Magazine Series 5, 50:302, 53-68, DOI: 10.1080/14786440009463891

To link to this article: http://dx.doi.org/10.1080/14786440009463891

曲 Published online: 21 Apr 2009.

Submit your article to this journal $ऍ$

Џ Article views: 11

Q View related articles $\square$ 
Postscript.-Since the above paper was written a valuable nemoir by Prof. Omori on "Seismic Experiments on the Freturing and Overturning of Columns" (Publications of the Earthquake Investigation Committee in Foreign Languages, No. 4, Tokyo, 1900, pp. 69-141), has reached this country. At the close of the memoir (pp. 137-141) he gives an "absolute scale of destructive earthquakes," the maximum acceleration corresponding to each degree being 300,900 , $1200,2000,2500,4000$, and more than $4000 \mathrm{~mm}$. per sec. per sec. respectively. The effects of a shock of each degree on buildings \&c. are described in detail. It appears also that the Japanese scale has been modified slightly since 1892. The form given by Prof. Omori is as follows, the corresponding degrees of the Rossi-Forel scale being added in brackets:Slight $(1,2)$, Weak (3 to 5), Strong $(6,7)$, Violent (8 to 10 and above).

IV. Elastic Constants of Rocks and the Velocity of Seismic Waves. By H. NAGAOKA, Professor of Applied Mathematics, Imperial University, Tökyö*.

THE vibration of the earth's crust has from time to time 1 been a favourite subject of discussion among the elasticians, and the propagation of seismic disturbance is a problem whose solution has long been hoped for, both from the theoretical and the empirical point of view. With improved instruments, seismologists have recently determined the velocity of propagation with tolerable accuracy, but very little is known of the elastic nature of the medium through which the vibration has travelled. The resources from which physicists and seismologists draw their theoretical inferences are so scanty, that among the numerous rocks which constitute the earth's crust, only a few of the most commonly occurring rocks have had their physical properties investigated. The questions of elasticity, having close bearing with the deformation of the earth's crust, have repeatedly been a subject of research by several distinguished elasticians as Lord Kelvin, Boussinesq, Cerruti, and Chree. But we are baffled in our attempt to apply the result of subtle analysis to the actual problem, from the lack of experimental knowledge as regards the elastic nature of the diverse rocks which compose the outer coating of our planet. The present experiments were undertaken with a view to fill these gaps, and to supply

* Reprinted from the Publications of the Earthquake Investigation Committee in Foreign Languages, no. 4. Communicated by the Author. 
on the one hand the wants of physicists, whose aim is to apply dynamics to the study of the geological phenomena, and on the other to meet the needs of seismologists, engaged in solving the problems touching the propagation of seismic waves.

Preparation of the Specimens.-The present experiments deal principally with the determination of Young's modulus and the modulus of rigidity, made on specimens of rocks which were easily accessible.

The number of rocks examined amounted to about eighty different specimens collected from various localities. These rocks were first cut in the shape of a rectangular parallelepiped, and afterwards carefully polished into prisms of nearly 1 centim. square cross-section and 15 centim. length. It was at first proposed to experiment with much larger specimens, but it was generally found impossible to find a large homogeneous piece with no trace of cleavage; in addition to this, the apparatus with which the elastic constants were to be measured would become cumbrously large, and require great solidity, increasing at the same time the difficulties of experiment.

Most of the specimens were apparently isotropic, but on close examination it was found that the isotropy was only superficial. Rocks as slates with distinct sedimentation planes were generally cut parallel and perpendicular to them ; where such planes of symmetry were not easily discernible, the specimen was conveniently cut into prisms.

The thickness of these prisms was measured by a contact micrometer reading, by means of a vernier, to $\frac{1}{100}$ millim. at three different places in the middle line of two opposite faces; namely, one at the middle and two at one quarter distance from the ends. The mean density of the prism was measured by dividing the mass by the volume, which was calculated from the known length and thickness. The density of several prisms cut from the same sample did not generally agree, showing that the material was only roughly homogeneous.

Modulus of Elasticity.-Young's modulus was measured by flexure experiment. The specimen to be tested was placed on two steel wedges, which served as fulcrums. The edge of the wedge was slightly rounded in order to prevent cutting on applying heavy weights. The flexure due to the weight hung at the middle of the prism was measured by means of a scale and telescope. By a special arrangement, a plane mirror was attached to the prism at the place where it rested on the wedges. The mirror was nearly vertical and the image 
of the vertical scale divided in millim., and placed at a distance of $2.73 \mathrm{~m}$., was observed by a telescope provided with a filar micrometer. By this means, the deflexion of $1^{\prime \prime}$ was easily measurable.

Denoting the length and the thickness of the prism by $b$ and c respectively, the distance between the fulcrums by $a$, and the angle of deflexion by $\delta$, we obtain for the modulus of elasticity $\mathrm{E}$

$$
\mathrm{E}=\frac{3 \mathrm{~W} a^{2}}{4 b c^{3} \delta},
$$

where $W$ stands for the weight suspended in the middle of the prism.

The elastic heterogeneity of rocks called for the necessity of examining the constants in different directions ; for this purpose, the prism was placed on its different faces on the fulcrum and the moduli for two mutually perpendicular directions were generally measured. These are denoted by $\mathrm{E}_{1}$ and $\mathrm{E}_{2}$ in the table of the elastic constants, and the menn of these two by $E$.

Modulus of Rigidity. - The modulus of rigidity was determined by measuring the amount of torsion produced by a given couple. It would lead too far were I to attempt to describe
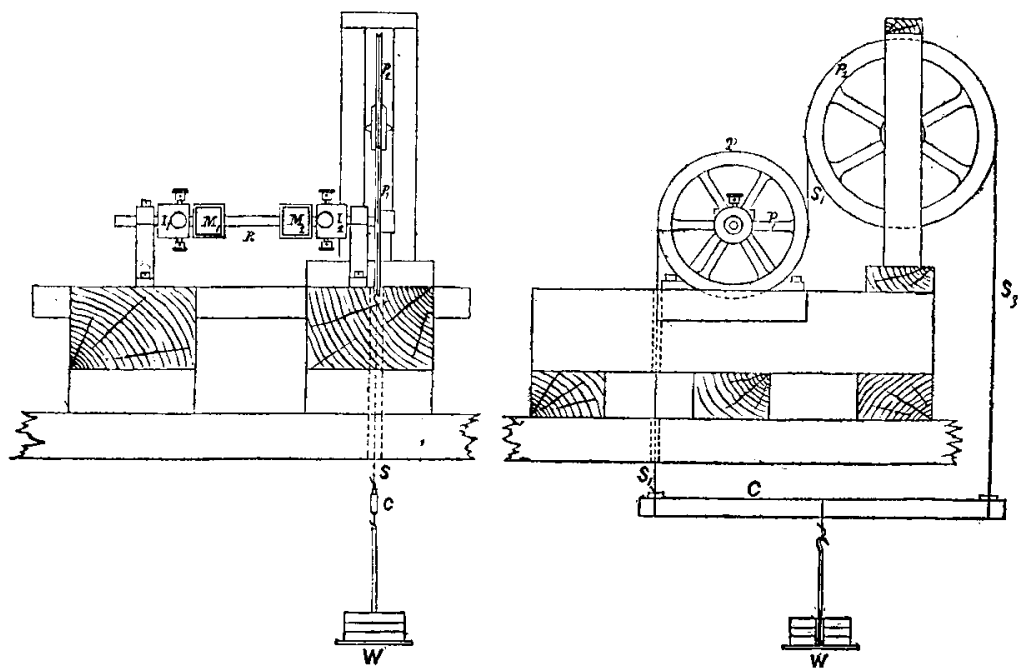

the details of the instrument. The rectangular prism $R$ was placed horizontal and firmly clamped at both its extremities to two solid pieces, $I_{1}, I_{2}$ of iron. In order to prevent cracking by too firmlv clamping, four small pieces of brass plate 
with thin sheet lead underneath were interposed between the four faces of the prism and the clamping screws. $I_{I}$ was fixed to a solid iron frame. The central steel cylinder protruding from $\mathrm{I}_{2}$ was filed down to a sharp knife-edge on its axis, coinciding with the central line of the prism. An agate plane attached to another solid iron frame supported the knifeedge and the twisting pulley $P$. To the cylinder above referred to, a pulley $\mathrm{P}_{1}$ of 14 centim. diameter was firmly fixed ; a flexible string $s_{1}$ attached to a pin $p$ on the circumference of the pulley passed over it, and was tied to a light wooden cross-bar $c$. Another string $s_{2}$ was attached to the pulley, and instead of passing over it, was slung around. another pulley $\mathrm{P}_{2}$ such that the line of passage $s_{2}$ from $\mathrm{P}_{1}$ to $P_{2}$ was vertical. The string on going over $P_{2}$ in the opposite direction to the former string was again let down vertical and attached to the cross-bar. By hanging the weight at the middle of the bar, the tension was the same in both strings and gave rise to a couple $=$ radius of the pulley $\times$ weight. By this arrangement, the knife-edge did not support the load producing the twisting couple, that of the prism, clamp, and pulley being the only weight acting. The amount of torsion was measured by observing the deflexion of two mirrors $M_{1}$ and $M_{2}$, one attached to the prism near the fixed clamp $I_{1}$ and the other near $I_{2}$. The deflexions, as measured by a vertical scale and two telescopes, were generally large compared with those in flexure experiments, so that no micrometric measurement was needed. The difference between the two scale-readings gave the torsion between the two places where the mirrors were fixed by special clamp screws.

Denoting the sides of the prism by $b$ and $c$, the torsion for unit length by $\tau$, the twisting couple by $\mathrm{N}$, and the rigidity by $\mu$, we get by St. Venant's formula for the torsion of a rectangular prism the following expression for $\mathrm{N}$

$$
N=\mu \tau b^{3} c\left\{\frac{16}{3}-\frac{b}{c}\left(\frac{4}{\pi}\right) \Sigma \frac{1}{(2 n-1)^{5}} e^{e} \frac{-e^{\left(\frac{2 n-1}{2 b}\right)^{\pi c}}}{e^{-\left(\frac{2 n-1}{2 b}\right)^{\pi c}}+e^{-\left(\frac{2 n-1}{2 b}\right)^{\pi c}}}\right\} .
$$

It may be a question whether it is justifiable to use St. Venant's formula in the present experiment, as the boundary conditions are somewhat different from those considered by St. Venant in deducing the above result. As the length of the prism was large compared with its thickness, and as the twist $\tau$ was measured at points not very near the ends of the prism, the result given by using the above formula will not be materially 
different from the actual value. When the rock is of stratified structure and shows great difference in its elastic behaviour the formula will require modification, but in studying the elasticity of rocks in its broad features, the modulus of rigidity calculated in the above manner will not be far from the general mean. The calculation of the series involved in the above formula is somewhat tedious. Fortunately, St. Venant has calculated a table of

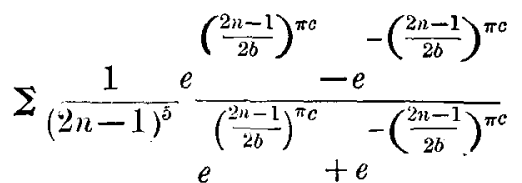

for different values of $\frac{c}{b}$. As the section of the prism was nearly square shaped, it was thought advisable to calculate the sum of the series at small intervals, when the ratio $\frac{c}{b}$ is nearly unity. As such tables will sometimes be found useful, I give the result of calculation in the following table :-

$$
\text { Table of } \frac{16}{3}-\frac{b}{c}\left(\frac{4}{\pi}\right)^{5} \Sigma \frac{1}{(2 n-1)^{5}} e^{\frac{\left(\frac{2 n-1}{2 b}\right)^{\pi c}}{e^{\left.\frac{2 n-1}{2 b}\right)^{\pi c}}}+e^{-\left(\frac{2 n-1}{2 b}\right)^{\pi c}}}=\beta \text {. }
$$

\begin{tabular}{|c|c|c|c|}
\hline$\frac{c}{b}$. & $\beta$. & $\begin{array}{l}\frac{c}{b} .\end{array}$ & $\beta$. \\
\hline $\begin{array}{l}1 \cdot 00 \\
1 \cdot 01 \\
1 \cdot 02 \\
1 \cdot 03 \\
1.04\end{array}$ & $\begin{array}{l}2 \cdot 249 \\
2 \cdot 272 \\
2 \cdot 294 \\
2 \cdot 316 \\
2 \cdot 338\end{array}$ & $\begin{array}{l}1 \cdot 15 \\
1 \cdot 16 \\
1 \cdot 17 \\
1 \cdot 18 \\
1 \cdot 19\end{array}$ & $\begin{array}{l}2 \cdot 563 \\
2 \cdot 583 \\
2 \cdot 602 \\
2 \cdot 621 \\
2 \cdot 639\end{array}$ \\
\hline $\begin{array}{l}1.05 \\
1.06 \\
1.07 \\
1.08 \\
1.09\end{array}$ & $\begin{array}{l}2 \cdot 359 \\
2 \cdot 379 \\
2 \cdot 402 \\
2 \cdot 422 \\
2 \cdot 443\end{array}$ & $\begin{array}{l}1.20 \\
1.21 \\
1.22 \\
1.23 \\
1.24 \\
1.95\end{array}$ & $\begin{array}{l}2 \cdot 658 \\
2 \cdot 676 \\
2 \cdot 694 \\
2 \cdot 713 \\
2 \cdot 730 \\
2.71\end{array}$ \\
\hline $\begin{array}{l}1 \cdot 10 \\
1 \cdot 11 \\
1 \cdot 12 \\
1 \cdot 13 \\
1 \cdot 14\end{array}$ & $\begin{array}{l}2 \cdot 464 \\
2 \cdot 484 \\
2 \cdot 504 \\
2 \cdot 524 \\
2 \cdot 543\end{array}$ & & \\
\hline
\end{tabular}


Hooke's Law and Elastic A/ter-Effect.-Preliminary expe riments with granite showed that Hooke's law does not hold even for very small flexure and torsion, and that the aftereffect is very considerable when the prism is sufficiently loaded or twisted; the deviation from the direct proportionality between the strain and stress was incomparably great compared with that observed in common metals. This must be chiefly due to the low limit of elasticity, so that it is necessary to experiment only within narrow limits of loading: or twisting. These limits are widely different for different specimens of rocks, and the modulus of elasticity as well as that of rigidity was always determined with such stresses as, will approximately produce strains proportional to them.

The deviation from Hooke's law was prominent in certain specimens of sandstones, and it was more marked in torsion than in flexure experiments. In certain rocks it is indeed doubtful if anything like a proportionality between stress and strain can be found even for extremely small change of shape. On releasing these rocks from stress the return towards the former state is extremely small, showing that the elasticity of rocks is of very inferior order. The elastic yielding of rocks under continuous action of stress is very remarkable, as the following readings of the deflexion in the experiment on torsion will show.

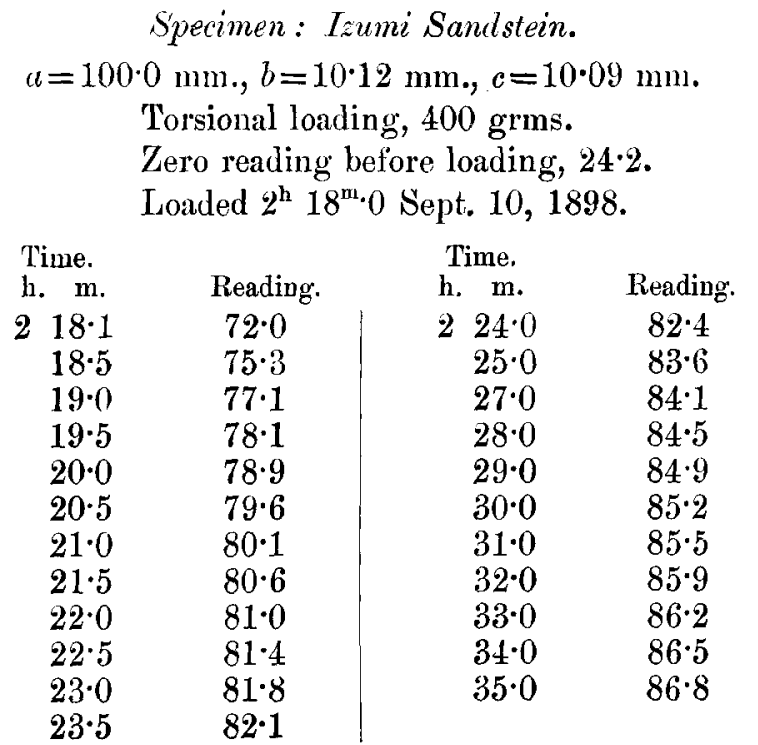


It will be seen that the initial deflexion amounts to $47.8 \mathrm{~mm}$.; the torsion of the prism gradually increases in course of a few minutes, so that after a lapse of about 19 minutes the increase of deflexion is nearly 30 per cent. of the initial. The increase becomes asymptotic with time.

The above-mentioned property of rocks will be of no small interest in dynamical geology, as it naturally illustrates the possibility of the folding of rocks and other kindred phenomena pertaining to the manifold change of shape in rocks, wrought by the continuous action of stress.

Velocity of Elastic Waves. - It was my intention to determine the modulus of elasticity, and then calculate the velocity of propagation of the longitudinal as well as that of the transversal waves, on the supposition that the material is isotropic. A few experiments with rocks of different ages showed that these attempts are for the most part fruitless, as the assumption of isotropy was not generally admissible. With archæan and palæozoic rocks it was possible to work them into proper shape for experiment only in a certain direction, as they were generally of schistose structure, and extremely brittle in the direction perpendicular to it; in such cases the elastic behaviour was of course widely different in these directions. Even with granite, which apparently is homogeneous in structure, the difference of elasticity with direction was noticed. On examination, these rocks were found to have been pressed from one side during formation, and this left its trace in the relation of strain to stress. For the complete discussion of the elastic nature of these rocks the determination of the moduli of elasticity and of rigidity considered as an isotropie substance is insufficient; we are in fact dealing with quasi-crystalline bodies, so that the number of elastic constants must depend on the number of symmetry-plines which can be drawn in these rocks. The type of the elastic waves travelling: in such a medium will be determined, when all of these constants are known. As we bave no simple means of examining these symmetry-planes, a single modulus of elasticity and rigidity was determined, on the supposition that the material is isotropic.

In the discussion of the propagation of seismic waves we have to deal with wave-lengths which measure over a kilometre. Geologists tell us that uniform strata of a kilometre thickness are of rare occurrence; and it may be doubted if these waves do not suffer change of type and shape in traversing the earth's crust. Unquestionably longitudinal plane waves whose velocity of propagation in an isotropic medium 
is given by the formula $\sqrt{\frac{\lambda+2 \mu}{\rho}}$ (following Lamé's notation) would seldom come into existence. A complete discussion of waves in quasi-crystalline rocks requires complicated analysis, which necessitates the knowledge of the elastic behaviour of rocks cut in various directions. 'To obtain a general view of the propagation I have thought it advisable to calculate $V_{l}=\sqrt{\frac{\bar{E}}{\rho}}$ for the longitudinal waves. Suppose the Young's modulus $\mathrm{E}$ is determined by flexure experiments on a prism eut parallel to a plane of symmetry, then $V_{l}$ will give the velocity of longitudinal waves travelling along the prism. The velocity in the sense above explained is given under $\mathrm{V}_{l}$, and the velocity of the transversal wave $\sqrt{\frac{\mu}{\rho}}$ under $V_{t} . \quad I$ do not mean to say that the actual velocity of longitudinal waves in various rocks is given by $\mathrm{V}^{l}$; but when such values are not obtainable, $\mathrm{V}_{l}$ will probably give a rough estimate. The elastic constants of rocks are tabulated in the order of geological age; for the same geological age those with larger velocity of propagation $V_{l}$ come before those with the slower.

Elastic Constants of Rocks.

\begin{tabular}{|c|c|c|c|c|c|c|c|c|}
\hline Rock. & $\begin{array}{l}\text { Spec. } \\
\text { No. }\end{array}$ & $\rho$. & $\mathrm{E}_{1}(\mathrm{c}, \mathrm{G}, \mathrm{s})$. & $\mathrm{E}_{2}$ (c.a.s.). & $\mathrm{E}$ (c.G.S.). & $\mu$ (C.G.S.). & $V l_{\text {Bec. }}^{\text {kilm. }}$ & $V_{t} \frac{\text { kilm }}{\text { sec. }^{\prime}}$ \\
\hline \multicolumn{9}{|c|}{ ARCHÆAN ROCKS. } \\
\hline \multirow{2}{*}{$\left.\begin{array}{c}\text { Chlorite Schist } \\
(\text { Chichibu) }\end{array}\right\}$} & 9 & 2977 & $112.1 \times 10^{10}$ & $132.4 \times 10^{20} \mid$ & $122.3 \times 10^{10}$ & $24.03 \times 10^{10}$ & $6 \cdot 40$ & $2 \cdot 84$ \\
\hline & 50 & $2 \cdot 955$ & $146 \cdot 0$ & $147 \cdot 6$ & 146.8 & $31 \cdot 57$ & $7 \cdot 05$ & $3 \cdot 27$ \\
\hline \multicolumn{9}{|c|}{ (Eruptive.) } \\
\hline $\left.\begin{array}{c}\text { Peridotite Ser- } \\
\text { pentine }(K u z i)\end{array}\right\}$ & 16 & $2 \cdot 825$ & $72 \cdot 92$ & $58 \cdot 99$ & 65.96 & $22 \cdot 24$ & $4 \cdot 83$ & $2 \cdot 81$ \\
\hline $\begin{array}{c}\text { Peridotite Ser- } \\
\text { pentine ..... } \\
\text { Ophicalcite ..... }\end{array}$ & $\begin{array}{l}41 a \\
41 b \\
45\end{array}$ & $\begin{array}{l}2 \cdot 777 \\
2 \cdot 786 \\
2 \cdot 593\end{array}$ & $\begin{array}{l}62 \cdot 42 \\
54 \cdot 15 \\
38 \cdot 90\end{array}$ & $\begin{array}{l}55.86 \\
53 \cdot 90 \\
53.71\end{array}$ & $\begin{array}{l}59 \cdot 14 \\
54 \cdot 03 \\
46 \cdot 31\end{array}$ & $\begin{array}{l}20.09 \\
19 \cdot 73 \\
\ldots \ldots\end{array}$ & $\begin{array}{l}4 \cdot 61 \\
4 \cdot 41 \\
4 \cdot 22\end{array}$ & $\begin{array}{l}2 \cdot 69 \\
2 \cdot 66 \\
\ldots \ldots\end{array}$ \\
\hline $\left.\begin{array}{cc}\text { Peridotite Ser- } \\
\text { pentine } & \ldots . . . .\end{array}\right\}$ & 17 & $2 \cdot 570$ & 39.03 & $46 \cdot 00$ & $32 \cdot 52$ & $16 \cdot 00$ & $4 \cdot 07$ & $2 \cdot 49$ \\
\hline
\end{tabular}


Rocks and the Velocity of Seismic Waves.

61

\begin{tabular}{|c|c|c|c|c|c|c|c|c|}
\hline Rock. & $\begin{array}{l}\text { Spec. } \\
\text { No. }\end{array}$ & $\rho$. & $\mathbf{E}_{1}$ (c.G.s.) & $\mathrm{E}_{2}$ (c.6.s.). & $\mathrm{E}(\mathrm{c}, \mathrm{G}, \mathrm{s})$. & $\mu$ (c.G.s.). & $\mathrm{v}_{l} \stackrel{\text { kilm. }}{\mathrm{\text {see }}}$ & $\nabla t \frac{\text { kilm. }}{\text { sec. }}$ \\
\hline \multicolumn{9}{|c|}{ PALAEOZOIC ROCKS. } \\
\hline $\left.\begin{array}{l}\text { Schalstein } \\
(\text { Rickuchy } \bar{u})\end{array}\right\}$ & 79 & $2 \cdot 653$ & $120.50 \times 10^{10}$ & $92.25 \times 10^{10}$ & $1064 \times 10^{10}$ & $18.90 \times 10^{10 !}$ & 632 & $2 \cdot 67$ \\
\hline $\begin{array}{r}\text { Clayslate } \\
(N i k k \hat{0})\end{array}$ & 74 & $2 \cdot 149$ & 7969 & $83 \cdot 29$ & $81 \cdot 49$ & $28 \cdot 06$ & $6 \cdot 16$ & $3 \cdot 61$ \\
\hline Schalstein & $\begin{array}{l}78 a \\
78 b\end{array}$ & $\begin{array}{l}2 \cdot 768 \\
2 \cdot 772\end{array}$ & $\begin{array}{l}70 \cdot 02 \\
97.90\end{array}$ & $\begin{array}{r}9500 \\
103 \cdot 30\end{array}$ & $\begin{array}{r}82 \cdot 51 \\
10060\end{array}$ & $\begin{array}{l}25 \cdot 26 \\
21 \cdot 25\end{array}$ & $\begin{array}{l}5 \cdot 45 \\
6 \cdot 02\end{array}$ & $\begin{array}{l}3 \cdot 03 \\
277\end{array}$ \\
\hline $\left.\begin{array}{c}\text { Sandy Slate } \\
(\text { Rikuchy } \bar{u})\end{array}\right\}$ & 73 & $2 \cdot 640$ & 8179 & $92 \cdot 40$ & $82 \cdot 10$ & 17.05 & 5.75 & 254 \\
\hline Clayslate...... & $\begin{array}{l}2 a \\
2 b \\
2 c\end{array}$ & $\begin{array}{l}2 \cdot 674 \\
2 \cdot 690 \\
2 \cdot 708\end{array}$ & $\begin{array}{l}98.00 \\
90.64 \\
51.92\end{array}$ & $\begin{array}{l}83 \cdot 09 \\
86 \cdot 71 \\
62 \cdot 26\end{array}$ & $\begin{array}{l}90 \cdot 55 \\
88 \cdot 68 \\
57.09\end{array}$ & $\begin{array}{l}13 \cdot 79 \\
20 \cdot 75 \\
20 \cdot 74\end{array}$ & $\begin{array}{l}5 \cdot 82 \\
5 \cdot 74 \\
4 \cdot 52\end{array}$ & $\begin{array}{l}2 \cdot 27 \\
278 \\
277\end{array}$ \\
\hline $\left.\begin{array}{l}\text { Limestone } \\
(\text { Musashi) }\end{array}\right]$ & 55 & 2630 & 84.95 & $88 \cdot 45$ & $86 \cdot 20$ & $29 \cdot 83$ & 574 & $3 \cdot 38$ \\
\hline Limestone ......... & 13 & $2 \cdot 653$ & $80 \cdot 20$ & $86 \cdot 61$ & $83 \cdot 40$ & $31 \cdot 00$ & $5 \cdot 60$ & 342 \\
\hline $\left.\begin{array}{l}\text { Limestone } \\
\quad \text { (Musashi) }\end{array}\right\}$ & 29 & $2 \cdot 682$ & $68 \cdot 86$ & $795 \tilde{5}$ & $74 \cdot 20$ & $21 \cdot 71$ & $5 \cdot 26$ & $2 \cdot 84$ \\
\hline $\begin{array}{l}\text { Weathered } \\
\text { Clayslate) }\end{array}$ & $\begin{array}{l}1 a \\
1 b\end{array}$ & $\begin{array}{l}2 \cdot 314 \\
2 \cdot 304\end{array}$ & $\begin{array}{l}62 \cdot 15 \\
56 \cdot 83\end{array}$ & $\begin{array}{l}61 \cdot 35 \\
58 \cdot 90\end{array}$ & $\begin{array}{l}61 \cdot 75 \\
57.87\end{array}$ & $\begin{array}{r}10 \cdot 03 \\
8 \cdot 85\end{array}$ & $\begin{array}{l}5 \cdot 18 \\
5 \cdot 01\end{array}$ & $\begin{array}{l}2.08 \\
1.96\end{array}$ \\
\hline Marble ........ & $11 a$ & $2 \cdot 654$ & $76 \cdot 0$ & $63 \cdot 72$ & 69.86 & $30 \cdot 11$ & $5 \cdot 13$ & 337 \\
\hline Schalsteir & $\begin{array}{l}11 b \\
80\end{array}$ & $\begin{array}{l}2 \cdot 625 \\
2 \cdot 824\end{array}$ & $\begin{array}{l}63 \cdot 53 \\
74.60\end{array}$ & $\begin{array}{l}46 \cdot 2 \\
70 \cdot 52\end{array}$ & $\begin{array}{l}54.86 \\
72.56\end{array}$ & $\begin{array}{l}2860 \\
18 \cdot 96\end{array}$ & $\begin{array}{l}4.54 \\
5.07\end{array}$ & $\begin{array}{l}3.45 \\
2.58\end{array}$ \\
\hline$(T o s a)$ & 75 & $2 \cdot 762$ & $57 \cdot 68$ & 37.70 & 47.69 & 898 & 463 & 1.80 \\
\hline Weatbered & $60 a$ & $2 \cdot 316$ & $39 \cdot 44$ & 35 & 37 . & 4.99 & $4 \cdot 02$ & $1 \cdot 47$ \\
\hline Clays & $60 b$ & $2: 306$ & $35 \cdot 37$ & & 36. & $5 \cdot 27$ & 396 & 151 \\
\hline Marble . & $12 a$ & 2650 & $37 \cdot 26$ & & $37 \cdot 45$ & 15.08 & 376 & $2 \cdot 39$ \\
\hline Clayslint & $\begin{array}{r}12 b \\
3 a\end{array}$ & $\begin{array}{l}2.650 \\
2384\end{array}$ & $\begin{array}{l}37 \cdot 33 \\
34 \cdot 48\end{array}$ & & & 1880 & $3 \cdot 93$ & $2 \cdot 66$ \\
\hline$(\operatorname{Tan} b a)$ & $\begin{array}{l}3 a \\
3 b\end{array}$ & \begin{tabular}{|}
2.384 \\
2392
\end{tabular} \mid & $\begin{array}{l}34 \cdot 48 \\
30 \cdot 64\end{array}$ & $\begin{array}{l}30 \cdot 76 \\
30.35\end{array}$ & $\begin{array}{l}32.62 \\
30 \cdot 50\end{array}$ & $\begin{array}{l}8.00 \\
8.54\end{array}$ & $\begin{array}{l}3 \cdot 70 \\
3.57\end{array}$ & $\begin{array}{l}1.83 \\
1.87\end{array}$ \\
\hline Clay- & $64 a$ & $2 \cdot 462$ & $30 \cdot 35$ & 28 & 29 & ....... & $3 \cdot 45$ & 171 \\
\hline & $64 b$ & $2 \cdot 416$ & 31 & & & & 361 & \\
\hline Weather & $7 a$ & 2.503 & 12. & 12 & 12 & $4 \cdot 60$ & 232 & $1 \cdot 36$ \\
\hline slate & $7 b$ & 2500 & 13. & & & & $2 \cdot 31$ & 1.31 \\
\hline Weathere & $65 a$ & $2 \cdot 490$ & 12. & 12. & 12 & 6 & $2 \cdot 24$ & $1 \cdot 63$ \\
\hline Clayslate & $65 b$ & $2 \cdot 500$ & $12 \cdot 54$ & 12 & $12 \cdot 51$ & $4 \cdot 43$ & $2 \cdot 24$ & $1 \cdot 33$ \\
\hline \multicolumn{9}{|c|}{ (Eruptive.) } \\
\hline $\left.\begin{array}{l}\text { Granite } \\
\quad(\text { Shödoshima })\end{array}\right\}$ & 69 & 2.572 & $37 \cdot 91$ & $46 \cdot 71$ & $42 \cdot 31$ & $18 \cdot 43$ & $4 \cdot 05$ & 268 \\
\hline Granite ............... & 42 & $2 \cdot 550$ & $31 \cdot 42$ & & & 13.99 & 3.51 & $2 \cdot 34$ \\
\hline (Hitachi). & 68 & 2549 & 18 & 20 & 19 & & 278 & $1 \cdot 64$ \\
\hline$\theta$ (Hitachi). & 71 & 2590 & 14 & 15 & & & $2 \cdot 42$ & $1 \cdot 40$ \\
\hline & 52 & $2 \cdot 503$ & 15 & 9. & 22 & 5 & $2 \cdot 22$ & $1 \cdot 48$ \\
\hline Granite (Hitachi). & 56 & $2 \cdot 530$ & 11.0 & 9 & $10 \cdot 93$ & $4 \cdot 43$ & 208 & $1 \cdot 32$ \\
\hline \multicolumn{9}{|c|}{ MESOZOIC ROCKS. } \\
\hline & 5 & $2 \cdot 216$ & $9 \cdot 2$ & $9 \cdot 0$ & $9 \cdot 1$ & $3 \cdot 1$ & $2 \cdot 03$ & $1 \cdot 18$ \\
\hline Sandstein & $\begin{array}{l}6 a \\
6 b\end{array}$ & $\begin{array}{l}2 \cdot 236 \\
2 \cdot 223\end{array}$ & $7 \cdot 1$ & $7 \cdot 2$ & $\begin{array}{l}7 \cdot 1 \\
7 \cdot 6\end{array}$ & 2 & $1 \cdot 78$ & $\begin{array}{l}1 \cdot 04 \\
1 \cdot 10\end{array}$ \\
\hline Schalstein ........ & 77 & 2778 & $75 \cdot 7$ & 83.0 & $79 \cdot 4$ & $23 \cdot 2$ & $5 \cdot 35$ & 289 \\
\hline $\left.\begin{array}{l}\text { Clayslate } \\
(\text { Rikuchyni })\end{array}\right\}$ & 72 & 2711 & $88 \cdot 4$ & 993 & $98 \cdot 8$ & $22 \cdot 6$ & $5 \cdot 88$ & $2 \cdot 89$ \\
\hline $\begin{array}{l}\text { Clayslate } \\
(\text { Rikuchy } \bar{u})\end{array}$ & 53 & 2702 & $83 \cdot 6$ & $85 \cdot 3$ & 84.5 & $18 \cdot 5$ & $5 \cdot 59$ & $3 \cdot 17$ \\
\hline $\begin{array}{l}\text { Clayslate } \\
\quad(\text { Tsushima })\end{array}$ & $\begin{array}{l}62 a \\
62 b\end{array}$ & $\begin{array}{l}2 \cdot 681 \\
2 \cdot 678\end{array}$ & $\begin{array}{l}32 \cdot 2 \\
43 \cdot 7\end{array}$ & $\begin{array}{l}50 \cdot 6 \\
44 \cdot 3\end{array}$ & $\begin{array}{l}41 \cdot 4 \\
44 \cdot 0\end{array}$ & $\begin{array}{l}14 \cdot 8 \\
14 \cdot 2\end{array}$ & $\begin{array}{l}3.91 \\
4.06\end{array}$ & $\begin{array}{l}2 \cdot 35 \\
2 \cdot 31\end{array}$ \\
\hline
\end{tabular}


62 Prof. H. Nagaoka on the Elastic Constants of

\begin{tabular}{|c|c|c|c|c|c|c|c|c|}
\hline Rock. & $\begin{array}{l}\text { 8pec. } \\
\text { No. }\end{array}$ & $\rho$. & $\mathrm{E}_{\mathrm{l}}$ (C.G.S.). & $\mathrm{E}_{2}$ (c, G.s.). & $\mathbf{E}$ (c.G.s.). & $\mu$ (c.e.s.). & $\nabla_{l} \frac{\text { kilm. }}{\text { sec. }}$ & $V_{t} \frac{\text { kilm. }}{\text { sec. }}$ \\
\hline \multicolumn{9}{|c|}{ GAINOHOIG ROCKS ('ertiary). } \\
\hline Rhyolite $(I z u)$ & 51 & $2 \cdot 316$ & $32.1 \times 10^{10}$ & $175 \times 10^{10}$ & $24.8 \times 10^{1 n}$ & $140 \times 10^{10}$ & $3 \cdot 24$ & $2 \cdot 46$ \\
\hline Rhyolite Tuff & $8 a$ & $2 \cdot 346$ & 21.9 & 21.5 & $21 \cdot 73$ & 932 & $3 \cdot 05$ & 1.99 \\
\hline (Iyo) & $8 b$ & $2 \cdot 316$ & $21 \cdot 8$ & 200 & 20.90 & 8.05 & $3 \cdot 01$ & 1.86 \\
\hline Tuff Sandstone & $19 a$ & $2 \cdot 305$ & $20 \cdot 6$ & $21 \cdot 1$ & $20 \cdot 8$ & $8 \cdot 74$ & 302 & 1.95 \\
\hline$(K \bar{\partial} z u k v)$ & $19 b$ & $2 \cdot 321$ & $21 \cdot 2$ & $21 \cdot 4$ & $21 \cdot 3$ & 845 & 302 & $1 \cdot 91$ \\
\hline Rhyolite & $59 a$ & $2 \cdot 472$ & $21 \cdot 3$ & $18 \cdot 7$ & $20 \cdot 0$ & $8 \cdot 57$ & $5 \cdot 85$ & $1 \cdot 86$ \\
\hline 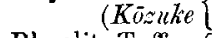 & $59 b$ & $2 \cdot 454$ & $19 \cdot 5$ & $18 \cdot 3$ & $18 \cdot 9$ & $9 \cdot 15$ & 278 & 1.93 \\
\hline Rhyolite Tuff & $63 a$ & $2 \cdot 228$ & $18 \cdot 8$ & $19 \cdot 9$ & $19 \cdot 3$ & $6 \cdot 9$ & $3 \cdot 00$ & $1 \cdot 79$ \\
\hline$(\operatorname{Mik} a w a)$ & $63 b$ & $2 \cdot 198$ & $17 \cdot 4$ & 118 & $14 \cdot 6$ & & $2 \cdot 59$ & \\
\hline Rhyolite $(I z u)$ & $27 a$ & $1 \cdot 945$ & $11 \cdot 3$ & $11 \cdot 7$ & $11 \cdot 5$ & $5 \cdot 78$ & $2 \cdot 43$ & $1 \cdot 72$ \\
\hline niyyone (1zu) & $27 b$ & $1 \cdot 944$ & $14 \cdot 0$ & $15 \cdot 1$ & $14 \cdot 6$ & $5 \cdot 86$ & 274 & $1 \cdot 74$ \\
\hline Rhyolite Tuff & 32 & 1.889 & $8 \cdot 1$ & $10 \cdot 1$ & $9 \cdot 1$ & $4 \cdot 2$ & $2 \cdot 20$ & $1 \cdot 49$ \\
\hline $\begin{array}{l}\text { Sandstone } \\
\qquad(C h o s h i)\end{array}$ & 58 & $2 \cdot 345$ & 109 & $11 \cdot 4$ & $11 \cdot 2$ & $4 \cdot 60$ & $2 \cdot 18$ & $1 \cdot 40$ \\
\hline $\begin{array}{r}\text { Rhyolite Tuff } \\
\text { (Amakusa) }\end{array}$ & 66 & $2 \cdot 263$ & $8 \cdot 0$ & $7 \cdot 59$ & $7 \cdot 80$ & $3 \cdot 59$ & $1 \cdot 86$ & $1 \cdot 26$ \\
\hline Rhyolite Tuff & $61 a$ & $2 \cdot 228$ & $10 \cdot 8$ & $11 \cdot 1$ & $10 \cdot 96$ & $6 \cdot 25$ & $2 \cdot 22$ & 1.51 \\
\hline (Iwashiro) & $61 b$ & $2 \cdot 198$ & $9 \cdot 8$ & $9 \cdot 6$ & $9 \cdot 67$ & $5 \cdot 66$ & $2 \cdot 10$ & $1 \cdot 67$ \\
\hline $\begin{array}{l}\text { Rhyolite Tuff } \\
\text { (Tochigi) }\end{array}$ & 43 & $1 \cdot 371$ & $1 \cdot 43$ & $2 \cdot 49$ & $1 \cdot 96$ & $1 \cdot 06$ & $1 \cdot 19$ & 0.89 \\
\hline Tuff...... & 36 & $1 \cdot 850$ & $35 \cdot 7$ & & & 6.235 & $4: 39$ & 1.84 \\
\hline Andesite........ & 54 & $2 \cdot 557$ & $43 \cdot 9$ & $45 \cdot 8$ & \pm 4.9 & $18 \cdot 50$ & $4 \cdot 19$ & $2 \cdot 69$ \\
\hline Andesite........ & 70 & $2 \cdot 462$ & $45 \cdot 5$ & 267 & $36 \cdot 1$ & $11 \cdot 69$ & 380 & $\mathbf{2} \cdot 18$ \\
\hline Tuff $\quad . . . . .$. & 30 & $2 \cdot 169$ & $28 \cdot 3$ & $27 \cdot 6$ & $27 \cdot 95$ & 10.99 & $3 \cdot 59$ & $2 \cdot 25$ \\
\hline Andesite.... & 15 & $2 \cdot 201$ & $29 \cdot 2$ & $23 \cdot 6$ & $26 \cdot 38$ & $12 \cdot 57$ & $3 \cdot 45$ & $2 \cdot 39$ \\
\hline Tuff ...... & 10 & $2 \cdot 283$ & $24 \cdot 3$ & $24 \cdot 9$ & 2462 & $10 \cdot 74$ & $3 \cdot 28$ & $2 \cdot 17$ \\
\hline Tuff & 14 & $2 \cdot 2 \div 2$ & $21 \cdot 6$ & $22 \cdot 8$ & $22 \cdot 2$ & $8 \cdot 48$ & $3 \cdot 18$ & $1 \cdot 96$ \\
\hline Andesite... & 28 & $2 \cdot 165$ & $19 \cdot 46$ & $27 \cdot 75$ & 2351 & $12 \cdot 15$ & $3 \cdot 24$ & $2 \cdot 37$ \\
\hline Andesite... & 39 & $2 \cdot 397$ & $23 \cdot 07$ & $20 \cdot 4$ & $21 \cdot 73$ & $10 \cdot 13$ & 3.01 & $2 \cdot 06$ \\
\hline Tuff $\ldots . .$. & 20 & $1 \cdot 859$ & $14 \cdot 4$ & $14 \cdot 5$ & $14 \cdot 41$ & $5 \cdot 07$ & 279 & $1 \cdot 65$ \\
\hline 'Tuff & $4 a$ & $1 \cdot 838$ & 10.9 & $11 \cdot 86$ & 11.40 & $4 \cdot 56$ & 299 & 1.58 \\
\hline $10 \mathrm{II}$ & $4 b$ & $1 \cdot 817$ & 120 & $12 \cdot 60$ & $12 \cdot 33$ & $3 \cdot 88$ & 260 & $1 \cdot 46$ \\
\hline Andesite. & 40 & $2 \cdot 302$ & 1476 & 326 & $13 \cdot 68$ & $5 \cdot 99$ & $2 \cdot 44$ & $1 \cdot 61$ \\
\hline Tuff & 57 & $2 \cdot 039$ & $11 \cdot 26$ & $10 \cdot 70$ & $10-98$ & $5 \cdot 51$ & 232 & $1 \cdot 65$ \\
\hline Andesite Tuff & $67 a$ & $2 \cdot 435$ & $13 \cdot 15$ & $12 \cdot 77$ & $12 \cdot 96$ & 578 & $2 \cdot 31$ & $1 \cdot 54$ \\
\hline (Echizen $)\}$ & $67 b$ & $2 \cdot 400$ & $13 \cdot 57$ & $13 \cdot 21$ & $13 \cdot 39$ & $5 \cdot 55$ & 2.37 & $1 \cdot 52$ \\
\hline Andesite.......... & 38 & $1 \cdot 943$ & $10-30$ & $10 \cdot 39$ & $10 \cdot 35$ & $4 \cdot 13$ & $2 \cdot 31$ & $1 \cdot 46$ \\
\hline Andesite... . . & 49 & $2 \cdot 158$ & $8 \cdot 96$ & $13 \cdot 1$ & $21 \cdot 0$ & $5 \cdot 26$ & $2 \cdot 26$ & $1 \cdot 56$ \\
\hline Andesite Tuff & 23 & 1.829 & $8 \cdot 23$ & $8 \cdot 48$ & $8 \cdot 36$ & $3 \cdot 92$ & $2 \cdot 14$ & $1 \cdot 46$ \\
\hline Andesite........ & 34 & $2 \cdot 022$ & $9 \cdot 17$ & $8 \cdot 44$ & $8 \cdot 81$ & $6 \cdot 00$ & $2 \cdot 09$ & 1.72 \\
\hline Andesite...... & 47 & $2 \cdot 425$ & $8 \cdot 51$ & $8: 38$ & $8 \cdot 45$ & $4 \cdot 06$ & 1.86 & $1 \cdot 29$ \\
\hline Tuff $(I z u) \ldots$ & 31 & $1 \cdot 915$ & $7 \cdot 53$ & $5 \cdot 82$ & $6 \cdot 68$ & $\ldots \ldots$ & $1 \cdot 86$ & ....... \\
\hline Tuff $\ldots . . . .$. & 33 & $1 \cdot 819$ & $6 \cdot 23$ & $6 \cdot 42$ & $6 \cdot 33$ & & $1 \cdot 87$ & \\
\hline Andesite $\ldots$ & 46 & $2 \cdot 574$ & 887 & $8 \cdot 36$ & $8 \cdot 62$ & 292 & 1.83 & 1.07 \\
\hline Andesite (lzu) & $25 a$ & $1 \cdot 984$ & 6557 & $5 \cdot 12$ & $5 \cdot 85$ & $1 \cdot 236$ & $1 \cdot 72$ & $0 \cdot 79$ \\
\hline & $25 b$ & $\mathbf{1} \cdot 632$ & $5 \cdot 57$ & $5 \cdot 14$ & $5 \cdot 36$ & 163 & $1 \cdot 60$ & $0 \cdot 88$ \\
\hline Andesite & 48 & $2 \cdot 102$ & 551 & $6 \cdot 81$ & $6 \cdot 16$ & $2-47$ & $1 \cdot 71$ & 1.08 \\
\hline Andesite Tuff. & 21 & $1 \cdot 497$ & 374 & $4 \cdot 12$ & $3 \cdot 93$ & $1 \cdot 39$ & $1 \cdot 62$ & $0 \cdot 97$ \\
\hline Tuff $(I z u) \ldots$. & 35 & $1 \cdot 286$ & $3 \cdot 45$ & $3 \cdot 31$ & $3 \cdot 38$ & $1 \cdot 50$ & $1 \cdot 62$ & $1 \cdot 08$ \\
\hline Tuff $(A w a) \ldots$ & 44 & $1 \cdot 448$ & $2 \cdot 72$ & 387 & $3 \cdot 30$ & $1 \cdot 17$ & $1 \cdot 50$ & $0 \cdot 90$ \\
\hline $\begin{array}{l}\text { ? Quartz Sand- } \\
\text { stone }\end{array}$ & 24 & $2 \cdot 138$ & $4 \cdot 04$ & $4 \cdot 05$ & $4 \cdot 05$ & $1 \cdot 30$ & $1 \cdot 37$ & $0 \cdot 78$ \\
\hline $\begin{array}{l}\text { ? Quartz Sand. } \\
\text { stone }\end{array}$ & 37 & $2 \cdot 230$ & $4 \cdot 02$ & $\cdots$ & $4 \cdot 02$ & & $1 \cdot 34$ & \\
\hline
\end{tabular}


Some of the specimens which hare been examined are nearly isotropic. Most of these rocks are of recent formation. For these I have calculated the velocities of propagation of longitudinal waves in unlimited medium

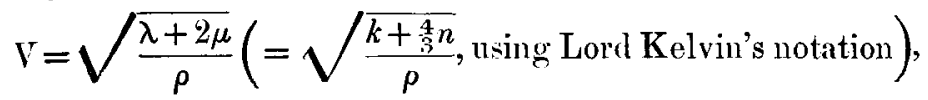

which are placed under the following table.

\begin{tabular}{|c|c|c|c|c|}
\hline Rock. & Age. & Density. & $\nabla=\sqrt{\frac{\lambda+2 \mu}{\rho}}\left(\frac{\mathrm{kilm} .}{\mathrm{sec} .}\right)$ & $V_{t}=V \frac{\mu}{\rho}$. \\
\hline 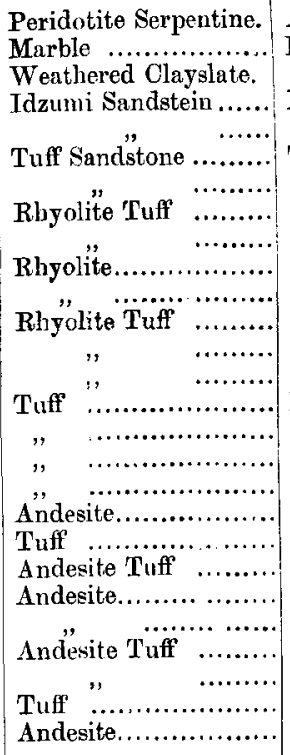 & 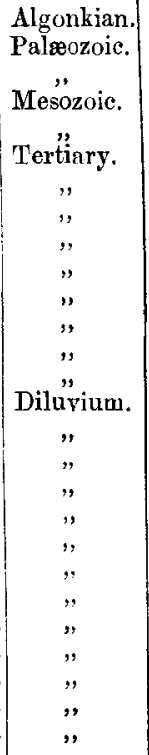 & $\begin{array}{l}2 \cdot 786 \\
2 \cdot 654 \\
2 \cdot 490 \\
2 \cdot 236 \\
2 \cdot 223 \\
2 \cdot 321 \\
2 \cdot 305 \\
2 \cdot 316 \\
2 \cdot 346 \\
1 \cdot 944 \\
2 \cdot 454 \\
2 \cdot 228 \\
2 \cdot 198 \\
2 \cdot 263 \\
2 \cdot 557 \\
2 \cdot 167 \\
2 \cdot 222 \\
2 \cdot 283 \\
2 \cdot 397 \\
1 \cdot 838 \\
2 \cdot 014 \\
2 \cdot 547 \\
1 \cdot 943 \\
2 \cdot 400 \\
2 \cdot 435 \\
2 \cdot 039 \\
2 \cdot 022\end{array}$ & $\begin{array}{l}5 \cdot 86 \\
4 \cdot 09 \\
2 \cdot 25 \\
2 \cdot 93 \\
2 \cdot 76 \\
3 \cdot 35 \\
3 \cdot 16 \\
3 \cdot 18 \\
3 \cdot 11 \\
3 \cdot 02 \\
2 \cdot 78 \\
2 \cdot 25 \\
2 \cdot 14 \\
1 \cdot 88 \\
4 \cdot 44 \\
4 \cdot 02 \\
3 \cdot 77 \\
3 \cdot 38 \\
3 \cdot 06 \\
2 \cdot 75 \\
2 \cdot 58 \\
2 \cdot 57 \\
2 \cdot 54 \\
2 \cdot 50 \\
2 \cdot 35 \\
2 \cdot 32 \\
2 \cdot 21\end{array}$ & $\begin{array}{l}2.68 \\
3 \cdot 37 \\
1.63 \\
1.04 \\
1 \cdot 10 \\
1.91 \\
1.95 \\
1.86 \\
1.99 \\
1 \cdot 74 \\
1.93 \\
1.51 \\
1.67 \\
1.26 \\
2.69 \\
2.25 \\
1.96 \\
2.17 \\
2.06 \\
1.58 \\
1.56 \\
1.77 \\
1.46 \\
1.52 \\
1.54 \\
1.65 \\
1.72\end{array}$ \\
\hline
\end{tabular}

I did not think it necessary to calculate the velocity of :urface-waves, which according to Lord Rayleigh amounts to $0.9554 \sqrt{\frac{\mu}{\rho}}$, as the difference of rigidity in different specimens is so great that the presence of the factor 0.9554 will not materially affect the result.

General Result.-In examining the elastic constants of rocks classified according to the age of formation, we find a distinct gradation as we pass from those of recent formation to the oldest. The increase of density, as well as the quasi-crystalline behaviour of rocks, is the most important characteristic of rocks which are deeply embedded in the 
earth's crust. The chlorite schist of Chichibu has a density nearly equal to 3 , although its modulus of elasticity is greater than that of brass or copper with a rod cut in the direction of strongest tenacity, it is so brittle in the direction perpendicular to it that it is impossible to obtain a single specimen with which the elastic constant can be accurately determined. The elastic constants are widely different as the specimen is cut in one or other direction, especially in archæan and palæoozoic rocks, as schists and slates with distinct sedimentation planes. Rocks of eruptive origin are generally free from such directional behaviour; but when they are pressed or otherwise subject to continuous application of stress, the difference of elasticity in different directions can still be traced. Such appears to be the case with marble and granite.

The elastic constants of archæan and palæozoic rocks are far superior to those of the cainozoic; but the velocity of propagation of longitudinal or transversal waves is not proportionally large. As the ratio of the elastic constant to density determines the velocity of propagation, we cannot at once conclude from the increase of elasticity that the waves travel with greater velocity. It would be too bold to draw anything like a general conclusion from the examination of some eighty specimens; but so far as the present experiments go, the tendency is such that the elastic constants increase more rapidly than the density as the rock becomes denser, and consequently elastie waves travel with greater velocity in the interior than on the surface of the earth's crust. Eruptive rocks are more isotropic than those of non-igneous origin, and have inferior elasticity; but there is the same distinction with age. Elastic waves in eruptive palæozoic rocks travel with slower velocity than in those of the archrean of the same origin ; a similar remark applies to cainozoic rocks with a few exceptions.

As we go deep in the earth's crust the rocks generally assume schistose structure; we have reason to believe that the elastic constants of the constituent rocks increase in a certain particular direction, which evidently coincides with that of swiftest propagation of elastic disturbance. Pressed by the weight of the superincumbent crust, these rocks will be of greater density; so that the increase of elastic constants is attended with corresponding increase of density. We cannot conceive that the elastic constant or the density will continually increase as we approach the centre of the earth ; they will both attain asymptotic values. The alternatives are: either the ratio of elastic constants to density goes on gradually increasing, or it first reaches a maximum and then 
goes on decreasing. The former supposition makes the velocity of elastic waves increase from the surface towards the centre of the earth, while the latter implies the existence of the stratum of maximum velocity of propagation. Such a stratum, if it exists, will lie pretty deep in the earth's crust, and will be inaccessible to us ; but the question will be settled by the seismologists.

Velocity of Propagation of Seismic Waves.-A glance at the table of elastic constants will show the complex elastic nature of rocks composing the earth's crust. The path pursued by waves of disturbance must necessarily assume very complicated forms, as they are subject to manifold reflexion, refraction, and dispersion. We can perhaps borrow analogy from a kindred optical phenomenon of curved rays in a medium of heterogeneous density, studied experimentally by Macé de Lépinay and Perot, and theoretically discussed by A. Schmidt and Wiener. The phenomena presented by the seismic wave will be of still more complex character as the medium is of quasi-crystalline nature, and the wave may suffer refraction something akin to that of light in Iceland-spar and arragonite. The elastic constants of rocks through which the disturbance propagates will rarely satisfy the condition of giving rise to purely longitudinal or distortional waves, so that the seismic wave will be of a mixed character. What Mr. Milne designates earthquake echoes or reverberations will partly find explanation in the intricate behaviour of diverse rocks in relation to the elastic wave travelling through them. The waves propagated from the centre of disturbance will appear on the seismograph as undulations of irregular periods, especially near the origin, At a distance waves of short period will gradually die out owing to the greater damping effect, while those of long period will still leare their mark, although not felt by us as a shock.

The investigation of the seismic waves affords the best means of feeling the pulse of the interior of the earth ; the elastic nature and the density distribution of the constituent rocks, or even the condition of the inaccessible depth, will in some future day be 'brought to light by the patient study of the disturbances, which traverse the strata of heterogeneous structure and appear as tremors or earthquakes on the earth's surface. I think the introdnction of the horizontal pendulum is a great progress in that branch of study which relates to the earth's interior, not that it records the apparent surface-movement of the soil, but that it does not fail to record earthquakes of distant origin, which, thongh insensible to us, sometimes appear as slow waves of gigantic Phil. Mag. S. 5. Vol. 50. No. 30z. July 1900. F 
amplitude. By it will be found disturbances which come throngh various strata, and probably those travelling through the stratum of maximum velocity of propagation.

Seismic waves travelling through strata of heterogeneous elasticity and density will generally be not purely longitudinal as in the case of sound, nor purely transversal as in the case of light, but a mixture of these two kinds. The velocity of propagation expressed as a function of elastic constants and density is not a simple problem : and moreover we do not possess sufficient experimental data to test the result of calculation. The formula $V_{l}=\sqrt{\frac{\mathrm{E}}{\rho}}$ for longitudinal waves in a thin rod will give a rough estimate of the velocity.

From records taken in Italy and Japan, Prof. Omori concludes that the velocity of the first tremor is almost always equal to 13 kilometres per sec. The question naturally arises : how can we account for such an enormous rate of propagation? The velocity of plane longitudinal waves in an infinite medium of steel is about 6.2 kilometres per second; if we take a rod of steel in place of an uniform medinm and give a blow to one of its ends, the longitudinal wave will travel with a velocity of 5.3 kilometres; if the same experiment be repeated on a piece of iron pyrites cut parallel to its axis of greatest elasticity, the velocity will be 8.4 kil. per second; in topaz, it will amount to 9 kilometres. Thus even with substances easily accessible on the earth's surfice, we have instances of elastic waves travelling with a velocity of something like 10 kilometres. In the present experiments the velocity in several primeval rocks ranges from 6 to 7 kil. per second; as we go deeper in the crust, we may not fail to find those rocks whose elastic constants are several times greater than those near the surface. So far as I am aware, iron pyrites has the greatest modulus of elasticity among the substances which have till now been placed under experimental test; it is about 1.6 times greater than in steel, and amounts to $3.5 \times 10^{12}$ c.G.s. units (Voigt). If we now imagine a stratum in which Young's modulus exceeds that of iron pyrites as much as that of iron pyrites exceeds that of steel, we shall obtain a velocity arrived at by seismologists, if density is not at the same time increased so much as to bring down the rate of propagation. The velocity of 13 kilometres per second, which is that calculated from the preliminary tremors, roughly corresponds to $\mathrm{E}=6.0 \times 10^{12}$ and $\rho=3.5$. To speak of the relation between density and elastic constant might seem a little absurd, but in the rocks so far examined, 
a certain relation between these two physical constants seems to exist. Comparing the elastic constants of cainozoic and archæan rocks, we find that with the increase of density from 2 to 3 , the modulus of elasticity has increased more than ten times in certain specimens. Thus it would not be a wild conjecture to put $\mathrm{E}=6 \times 10^{12}$ when the density is 3.5 . As the mean density of the earth is little over $5 \cdot 5$, we shall come across a stratum of the density above cited not very far from the surface. These considerations give support to the view above stated that there is a stratum of maximum velocity of propagation.

From the minute study of the records of distant earthquakes, Prof. Omori found that in the intermediate position between the first tremor and the principal shock, there is almost always a slight abrupt change in the seismograph record. The velocity of propagation for this kind of disturbance is about 7 kilometres per second. If we suppose that the interior of the earth consists of an isotropic substance, and that the longitudinal wave travelling through it gives rise to the first tremor, and the transversal to the second, we can easily find the Poisson ratio of the hypothetical interior. Obviously

$$
\sqrt{\frac{\lambda+2 \mu}{\mu}}=\frac{13}{7}
$$

and the ratio of lateral contraction to longitudinal extension

$$
\sigma=\frac{\lambda}{2(\lambda+\mu)}=0 \cdot 298 .
$$

This value is nearly the same as that generally attributed to iron, glass, and other isotropic substances. In his paper on the Application of Physics and Mathematics to Seismology (Phil. Marg. 1897), Dr. Chree supposes that the velocity of 12.5 kilometres belongs to the longitudinal wave, that of 2.5 to the transversal, and adduces proof that the substance in the interior of the earth offers enormous resistance to compression. On the above supposition, Young's modulus turns out to be $100 \times 10^{10}$ C.G.s. units, which is less than that observed on chlorite schist. It seems quite nnlikely that the elastic constants of the deeply-seated material should be less than those within a few thousand feet of the earth's crust. In addition to this, we have to remark that the disturbance whose velocity is greater than 10 kilometres is very small compared to that of the principal shock, which is generally 3 kilometres; and we have no ground to suppose that the effect of the trans? versal wave is greater than that of the longitudinal. On the hypothesis that the interior of the earth consists of homo- 
geneous substance, as Dr. Wiechert assumes it to be, it is quite probable that the velocity of the longitudinal wave is 13 kilometres, and that of the transversal wave is about 7 kilometres, as found by Prof. Omori. These velocities are nearly twice as great as those observed in the oldest rocks here examined.

Elastic waves travel with slow velocity in surface rocks. If the principal shocks in the seismometer-record be taken into account, the velocity turns out to be very small and about 3.3 kilometres. This evidently is about the mean velocity of propagation in most of the surface rocks, and shows that waves of large amplitude creep along the surfuce. It is not wonderful that with distant earthquakes, the duration sometimes extends over several hours, as the disturbance travels through strata of different elastic constants, and the waves modified in varions ways will appear all blended together on the seismograph. Although 3 kilometres may be a mean velocity, there are certain surface rocks in which the velocity is less than a kilometre. The shock at the epicentre may last only for a short time, but the duration at a distance will be lengthened, as the range of velocity is very wide. The disturbance coming from the strata of greatest rate of propagation will first make its appearance at the beginning of the preliminary tremor, followed by waves travelling with slower velocity till the principal shock arrives as surface waves. It will be followed by waves travelling with still slower velocity leaving faint record on the seismograph, till they at length fade away. Neglecting the time of passage from the stratum above mentioned to the surface, it is natural to expect that the duration of the so-called preliminary tremor preceding the earthquake shock increases linearly with the distance of the epicentre from the place of observation. The above relation was established from various earthquakes which happened in Japan, recorded by Prof. Omori.

With great earthquakes which are perceptible on a seismograph at very great distances, the duration will continually increase with distance; the disturbance may sometimes propagate still unabated in one or other direction round the earth. If the last-mentioned case actually takes place, the tremor will probably last even for days. As such reeords have sometimes been obtained by seismologists, it may not be out of place here to notice the possibility for such undulatory movement of the ground.

In conclusion, I wish to express my thanks to Prof. Koto and Mr. Fukuchi for valuable information concorning the geological and petrological character of rooks examined in the present experiment. 